\title{
Distinction and Quantitation of Sugar Isomers in Ternary Mixtures Using the Kinetic Method
}

\author{
Thierry Fouquet and Laurence Charles \\ Universités Aix-Marseille I, II, and III - CNRS, UMR 6264: Laboratoire Chimie Provence, Spectrométries \\ Appliquées à la Chimie Structurale, Marseille, France
}

Quantitative isomeric analysis of fructose, galactose, and glucose was achieved using electrospray ionization and trimeric ion dissociation with data analysis by the kinetic method. Several L-amino acids and divalent metal cations were tested to select the best systems for isomeric distinction and quantitation of each monosaccharide. High discrimination could be achieved for most tested systems, and serine $/ \mathrm{Cu}^{2+}$ and aspartic acid/ $\mathrm{Mn}^{2+}$ were selected for quantitative analysis due to their ability to strongly distinguish the three analytes and to allow long-term reproducible measuring conditions. Accurate quantitative results were obtained for all isomers using three-point corrected calibration curves, which account for the competition effects evidenced to occur between sugars for the formation of the trimeric complexes. As a result, the relative proportion of one isomer in the liquid and in the gas phase depends on the sugar mixture composition. However, for a given reference/metal system, the extent of competition effects was shown to be constant within a given pair of sugars. The correction factors could thus be established based on data obtained from binary mixtures and successfully used for ternary sample analysis. (J Am Soc Mass Spectrom 2010, 21, 60-67) (C) 2010 American Society for Mass Spectrometry

C arbohydrates are ubiquitous compounds and are involved in a wide array of biological roles. In addition to the storage and transport of energy, carbohydrates and their derivatives are structural elements in cell walls and were recently shown to play a vital role in cell-cell interactions [1, 2]. It is becoming more obvious in recent years that carbohydrates present a new dimension in drug design for targeting specific diseases [3]. Various carbohydratebased drugs are currently in use, amongst which Heparin as anti-coagulant or Tamiflu for treating influenza [4]. In addition, monosaccharides have been investigated for their in vivo anti-inflammatory and cardioprotective effects [5] and also as drug carriers [6]. While qualitative structural distinction of sugars is a crucial issue in biochemistry studies, their precise quantitative analysis is also a very important step in the conversion of biomass feedstocks to fuels and chemicals.

Nuclear magnetic resonance (NMR) has the ability to distinguish sugars as analyzed from individual solution but the complexity of NMR signals rapidly increases for mixture analysis. Chromatographic methods are also widely used to separate monosaccharide isomers [7, 8] or enantiomers [9] but are usually time-consuming. Significant progress has been made on sugar analysis based exclusively on mass spectrometry. Qualitative

Address reprint requests to Dr. L. Charles, Spectrométries Appliquées à la Chimie Structurale, Campus Saint-Jérôme, Case 511, 13397 Marseille Cedex 20, France. E-mail: laurence.charles@univ-provence.fr distinction of underivatized isomeric monosaccharides was reported based on differences observed during collision-induced dissociation of molecular ionic adducts [10] or metal complexes [11-13]. In contrast, quantitative chiral analysis of sugars was demonstrated using the kinetic method [14]. Originally developed for differentiation and quantitation of enantiomers in mixture [15], the kinetic method has also been successfully applied for the distinction of isomeric peptides [16-19] or amino acids [20], and is aimed at being tested here for quantitation of monosaccharide isomers.

The fundamental concept of isomeric mixture analysis is based on the kinetics of competitive unimolecular dissociation of metal ion-bound clusters. Singly charged trimeric cluster ions, $\left[\mathrm{M}^{\mathrm{II}}(\operatorname{Ref})_{2}(\mathrm{~A})-\mathrm{H}\right]^{+}$, consisting of a divalent cation $\left(\mathrm{M}^{\mathrm{II}}\right)$, two molecules of a reference compound (Ref), and one analyte molecule (A), are first generated by electrospray ionization (ESI). When activated upon collision, such trimeric clusters usually dissociate to form two dimeric complexes, i.e., $\left[\mathrm{M}^{\mathrm{II}}(\operatorname{Ref})(\mathrm{A})-\mathrm{H}\right]^{+}$after elimination of a neutral reference and $\left[\mathrm{M}^{\mathrm{II}}(\mathrm{Ref})_{2}-\mathrm{H}\right]^{+}$by the loss of a neutral analyte. Different isomeric configurations of the analyte should induce differences in stability of the product ion $\left[\mathrm{M}^{\mathrm{II}}(\operatorname{Ref})(\mathrm{A})-\mathrm{H}\right]^{+}$, resulting in differences in the corresponding product ion abundance measured relative to the abundance of $\left[\mathrm{M}^{\mathrm{II}}(\operatorname{Ref})_{2}-\mathrm{H}\right]^{+}$. A relative branching ratio $R_{\mathrm{i}}$ for the two competitive dissociation channels can thus be defined for each $A_{i}$ isomer as (eq 1): 


$$
R_{\mathrm{i}}=\left[\mathrm{M}^{\mathrm{II}}(\operatorname{Ref})\left(\mathrm{A}_{\mathrm{i}}\right)-\mathrm{H}\right]^{+} /\left[\mathrm{M}^{\mathrm{II}}(\operatorname{Ref})_{2}-\mathrm{H}\right]^{+}
$$

The efficiency of a system to distinguish two $A_{i}$ and $A_{j}$ isomers, defined as $R_{\text {iso }}$, is obtained by calculating the ratio of $R_{\mathrm{i}}$ to $R_{\mathrm{j}}$. The more the $R_{\mathrm{iso}}$ value differs from unity, the higher the degree of isomer distinction while $R_{\text {iso }}=1$ indicates a lack of discrimination. In binary mixtures of $A_{i}$ and $A_{j}$ isomers, the relationship between the relative branching ratio $(R)$ and the molar fraction of one $\mathrm{A}_{\mathrm{i}}$ isomer $\left(\alpha_{\mathrm{i}}\right)$ is derived from the kinetic method expression [21, 22] as (eq 2):

$$
\ln R=\alpha_{\mathrm{i}} \cdot \ln R_{i}+\left(1-\alpha_{\mathrm{i}}\right) \cdot \ln R_{\mathrm{j}}
$$

In the case of a ternary mixture of $A_{i}, A_{j}$, and $A_{k}$ isomers, eq 2 takes the form shown as (eq 3 ):

$$
\ln R=\alpha_{\mathrm{i}} \cdot \ln R_{i}+\alpha_{\mathrm{j}} \cdot \ln R_{j}+\left(1-\alpha_{\mathrm{i}}-\alpha_{\mathrm{j}}\right) \cdot \ln R_{\mathrm{k}}
$$

which requires the analytes to be measured under different conditions to obtain two sets of equations to solve this two unknown system [17].

In this study, the capability of the kinetic method to rapid isomeric distinction and quantitation of monosaccharides is explored, using D-glucose, Dgalactose, and D-fructose (Scheme 1) as examples. The search for two discriminant reference/metal systems is presented, as well as the methodology implemented for quantitation of each monosaccharide in binary and ternary mixtures.

\section{Experimental}

\section{Chemicals}

All chemicals used in this study were purchased from Sigma-Aldrich (Saint Louis, MO, USA) and were used without further purification. D-sugar isomers studied as the analytes were fructose (fru), galactose (gal), and glucose (glc), and isotopically labeled sugars contain a ${ }^{13} \mathrm{C}$ in position 1 . L-amino acids tested as references were arginine (Arg), asparagine (Asn), aspartic acid (Asp), glutamic acid (Glu), glutamine (Gln), phenylalanine (Phe), serine (Ser), threonine (Thr), and tyrosine (Tyr). Salts utilized to introduce a divalent cation in solution were $\mathrm{Ca}\left(\mathrm{NO}_{3}\right)_{2}, \mathrm{MnCl}_{2}, \mathrm{FeSO}_{4}, \mathrm{Co}\left(\mathrm{CH}_{3} \mathrm{COO}\right)_{2}$, $\mathrm{ZnCl}_{2}$, and $\mathrm{CuSO}_{4}$. HPLC-grade water was purchased from SDS (Peypin, France) and HPLC-grade methanol was from Sigma-Aldrich. Electrosprayed samples were aqueous methanol solutions consisting of a mixture of

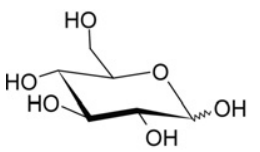

D - glucopyranose

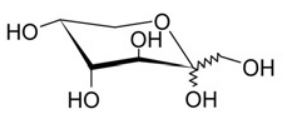

D - fructopyranose

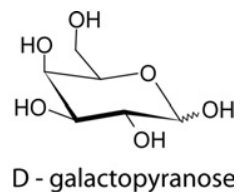

D - galactopyranose
Scheme 1. Chemical structure of the studied monosaccharide isomers. sugar $\left(2 \times 10^{-4} \mathrm{~mol} \mathrm{~L}^{-1}\right)$, a reference compound $(2 \times$ $\left.10^{-4} \mathrm{~mol} \mathrm{~L}^{-1}\right)$, and a transition-metal $\left(1 \times 10^{-4} \mathrm{~mol}\right.$ $\left.\mathrm{L}^{-1}\right)$.

\section{Mass Spectrometry}

MS and MS/MS experiments were performed with a 3200 Q-TRAP mass spectrometer (Applied Biosystems SCIEX, Concord, ON, Canada) equipped with an electrospray ionization source operated in the positive mode. The capillary voltage was set at $5500 \mathrm{~V}$ and the cone voltage at $20 \mathrm{~V}$. In this hybrid instrument, quadrupole configuration was set for both analyzers in collision-induced dissociation (CID) experiments. Each spectrum was the result of 50 scan accumulations. Air was used as the nebulizing gas (10 psi) whereas nitrogen was used as the curtain gas (10 psi) as well as the collision gas. Collision energy was set at the minimal value of $5 \mathrm{eV}$ (laboratory frame). Instrument control, data acquisition, and data processing of all experiments were achieved using Analyst software (ver. 1.4.1) provided by Applied Biosystems. Sample solutions were introduced in the ionization source at a $5 \mu \mathrm{L} \mathrm{min}^{-1}$ flow rate using a syringe pump.

\section{Results and Discussion}

Although there is no strict rule allowing prediction of the proper reference/metal system that would actually discriminate pairs of isomers, some empirical guidelines have been established based on experimental results from numerous previously reported studies. When aimed at achieving chiral recognition, transitionmetal ions are usually employed to generate the trimeric clusters since they allow the analyte and the reference to be bound together in a polydentate complex with multiple point interactions [23]. As a result, $\mathrm{Co}^{2+}$, $\mathrm{Cu}^{2+}, \mathrm{Fe}^{2+}$, and $\mathrm{Zn}^{2+}$ were selected here as the central metal cations since they were reported to readily form complexes with oxygen- and nitrogen-containing compounds [24]. $\mathrm{Ca}^{2+}$ and $\mathrm{Mn}^{2+}$ were also tested since they were shown to readily adduct carbohydrates in ESI [25]. The similarity of the reference and the analyte in terms of metal affinities was shown to allow trimeric clusters to form easily and thus accurate relative abundance ratios to be measured. However, these data are often unknown and the use of proton affinity is not always a consistent measure of the metal ion affinity [26]. One underlying assumption of the kinetic method is that entropy effects on fragmentation are negligible, and this criterion is best satisfied when the reference compound and the analyte are of similar size and functionality [23]. Amino acids are very often used as reference molecules and a set of nine molecules was selected based upon their functional moieties: a hydroxyl function (serine, threonine and tyrosine), an additional acidic function (aspartic acid and glutamic acid), or an additional amine group (asparagine, glutamine and arginine). Phenylalanine was also tested since the use of such a 
reference containing an aromatic side chain was found to provide superior chiral recognition for amino acid analytes [15]. Both L- and D-amino acids were tested as references in this study. Reciprocal relationships were reported when switching the chirality of the reference in enantiomeric analysis using the fixed ligand kinetic method [27]. In contrast, similar results were obtained here regardless of the reference chirality, in terms of trimeric cluster formation and isomeric distinction (Table $1 S$ in Supplementary Material, which can be found in the electronic version of this article). As a result, only data using the L-amino acids have been reported.

All mixtures containing one sugar $\left(\mathrm{A}_{\mathrm{i}}\right)$, one reference compound (Ref), and one transition-metal $\left(\mathrm{M}^{\mathrm{II}}\right)$ were electrosprayed to check for the formation of the trimeric cluster ion, $\left[\mathrm{M}^{\mathrm{II}}(\operatorname{Ref})_{2}\left(\mathrm{~A}_{\mathrm{i}}\right)-\mathrm{H}\right]^{+}$, in the mass spectra. It should first be noted that tyrosine was removed from the list of tested references due to solubility issue in aqueous methanol. Some systems failed at generating the trimer of interest, as for example those including references such as arginine (with any metal) or glutamic acid (except when associated with $\mathrm{Ca}^{2+}$ ), as well as the combination of aspartic acid with $\mathrm{Co}^{2+}$. When the trimeric ions were observed, they were mass-selected in the first quadrupole of the instrument to be further submitted to CID in the collision cell. MS/MS data were recorded using the second quadrupole mass analyzer and used to calculate the relative branching ratio $R_{\mathrm{i}}$ (as defined in eq 1) for each system. Extensive secondary fragmentation of the targeted product ions was sometimes observed, as when using references such as phenylalanine (except when associated with $\mathrm{Cu}^{2+}$ or $\mathrm{Zn}^{2+}$ ) or serine (with all metals but $\mathrm{Cu}^{2+}$ ), as well as for the aspartic acid/copper system. In all cases, these secondary fragmentation reactions mostly arose from the sugar moiety and consisted of cross-ring cleavages leading to the loss of two or three formaldehyde molecules (as exemplified for $\left[\mathrm{Ca}^{\mathrm{II}}(\mathrm{L}-\mathrm{Phe})_{2}(\mathrm{D}-\mathrm{glc})-\mathrm{H}\right]^{+}$ trimeric cluster ion in Figure 1S,), as commonly reported in tandem mass spectrometric studies of saccharides [13, 28-30]. A protonated reference molecule was also systematically detected as an additional fragment ion. These systems were no longer considered since an underlying principle of the kinetic method is that the trimeric complex precursor ion should dissociate to form two dimeric cluster product ions exclusively, without other competitive or consecutive fragmentations [31]. Some trimeric cluster ions were shown to mainly eliminate the analyte as a neutral, thus preventing any $R_{\mathrm{i}}$ value to be calculated. This was the case for all combinations containing glutamine and asparagine (except when associated to $\mathrm{Ca}^{2+}$ ) and when the trimer ions were generated from mixtures containing phenylalanine and $\mathrm{Cu}^{2+}$. Nevertheless, these amino acids can be seen as promising reference candidates in the fixedligand version [32] of the kinetic method and will be tested as such in a forthcoming study. Finally, no $R_{\mathrm{i}}$ value could be calculated for those trimeric clusters that mainly dissociate via the loss of the reference neutral, as observed when combining any sugar with threonine and $\mathrm{Ca}^{2+}, \mathrm{Fe}^{2+}$, or $\mathrm{Cu}^{2+}$. A set of 11 systems could be validated for the calculation of relative branching ratios $R_{\mathrm{i}}$, further used to estimate their efficiency to distinguish two isomeric sugars, as measured by $R_{\text {iso }}$ (Table 1 ).

In the case of samples containing two analytes, the best systems are identified by $R_{\text {iso }}$ values the more different from unity. When three isomers are to be distinguished in mixtures, an additional requirement for a system to be discriminant is to have the most different $R_{\text {iso }}$ values for the three pairs. Based on data presented in Table 1 , systems containing $\mathrm{Zn}^{2+}, \mathrm{Co}^{2+}$, or $\mathrm{Fe}^{2+}$ as the central metal were not further considered due to a lack of distinction between D-glucose and D-fructose. The use of $\mathrm{Ca}^{2+}$, in particular when associated with aspartic acid (Asp) or glutamic acid (Glu) as the reference, was promising in terms of $R_{\text {iso }}$ values but has to be avoided since it was shown to induce a dry salt deposit, which rapidly blocked the orifice of the mass spectrometer. Finally, three systems could be envisaged for their ability to distinguish D-galactose, D-glucose, and D-fructose in mixtures (Ser/ $\mathrm{Cu}^{2+}, \mathrm{Asp} /$ $\mathrm{Mn}^{2+}$, and $\mathrm{Thr} / \mathrm{Mn}^{2+}$ ). In Table 1, the uncertainty

Table 1. Isomeric recognition of D-galactose (gal), D-glucose (glc), and D-fructose (fru) analytes $\left(\mathrm{A}_{\mathrm{i}}\right)$ using different metal cations $\left(\mathrm{M}^{\mathrm{II}}\right)$ and different amino acid references (Ref)

\begin{tabular}{|c|c|c|c|c|c|c|c|}
\hline \multirow[b]{2}{*}{$M^{\prime \prime}$} & \multirow[b]{2}{*}{ Ref } & \multicolumn{3}{|c|}{$\left[M^{\prime \prime}(\operatorname{Ref})\left(A_{i}\right)-H\right]^{+} /\left[M^{\prime \prime}(\operatorname{Ref})_{2}-H\right]^{+}$} & \multicolumn{3}{|c|}{$R_{\text {iso }}(\sigma)^{\mathrm{a}}$} \\
\hline & & gal & glc & fru & $\mathrm{gal} / \mathrm{glc}$ & gal/fru & glc/fru \\
\hline \multirow[t]{3}{*}{$\mathrm{Ca}^{2+}$} & Asp & 16.7 & 1.59 & 5.8 & $10.5(0.8)$ & $2.9(0.3)$ & $0.27(0.01)$ \\
\hline & Asn & 0.581 & 0.090 & 0.227 & $6.5(0.2)$ & $2.56(0.03)$ & $0.40(0.01)$ \\
\hline & Glu & 9.09 & 0.893 & 3.03 & $10.2(0.4)$ & $3.0(0.1)$ & $0.29(0.01)$ \\
\hline \multirow[t]{2}{*}{$\mathrm{Mn}^{2+}$} & Asp & 2.62 & 0.45 & 1.11 & $5.8(0.3)$ & $2.36(0.04)$ & $0.41(0.02)$ \\
\hline & Thr & 24 & 1.96 & 3.23 & $12(0.5)$ & $7.4(0.3)$ & $0.61(0.01)$ \\
\hline $\mathrm{Fe}^{2+}$ & Asp & 2.27 & 0.411 & 0.455 & $5.52(0.08)$ & $4.99(0.08)$ & $0.90(0.01)$ \\
\hline $\mathrm{Co}^{2+}$ & Thr & 9.26 & 0.746 & 0.557 & $12.4(0.2)$ & $16.6(0.2)$ & $1.34(0.02)$ \\
\hline $\mathrm{Cu}^{2+}$ & Ser & 0.420 & 0.161 & 0.043 & $2.61(0.05)$ & $9.8(0.3)$ & $3.7(0.1)$ \\
\hline \multirow[t]{3}{*}{$\mathrm{Zn}^{2+}$} & Asp & 1.43 & 0.317 & 0.312 & $4.51(0.08)$ & $4.58(0.09)$ & $1.02(0.03)$ \\
\hline & Phe & 4.2 & 0.192 & 0.172 & $21.9(0.6)$ & $24.4(0.6)$ & $1.12(0.02)$ \\
\hline & Thr & 4.17 & 0.392 & 0.42 & $10.6(0.2)$ & $9.9(0.3)$ & $0.93(0.03)$ \\
\hline
\end{tabular}

\footnotetext{
astandard deviation calculated on five replicate experiments.
} 
associated with $R_{\mathrm{i}}$ values (calculated from five replicate experiments) was not reported for the sake of clarity but is given for $R_{\text {iso }}$. Accordingly, the system consisting of threonine as the reference and $\mathrm{Mn}^{2+}$ as the central metal was not further used in this study since it was expected to affect the accuracy of quantitative results. Sugar isomeric distinction is illustrated in Figure 1, using serine as the reference and copper as the central metal. Interestingly, in contrast to most reported studies dealing with chiral recognition using the kinetic method, the

(a)

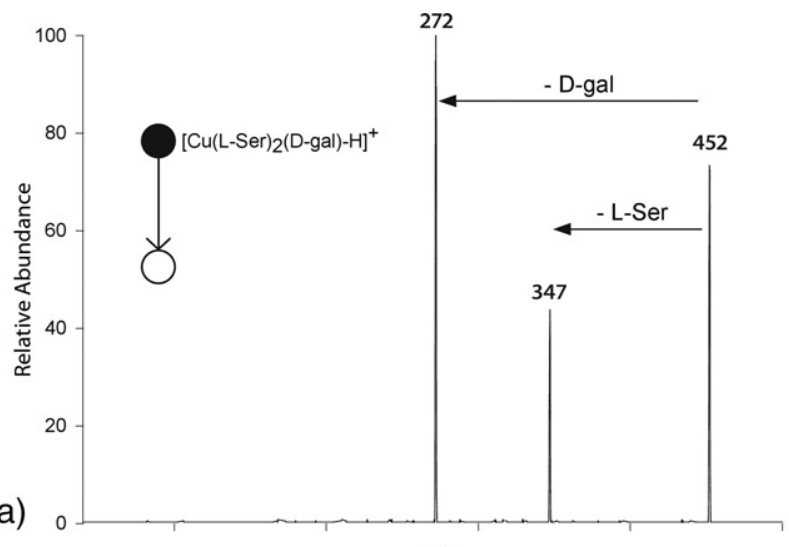

(b)

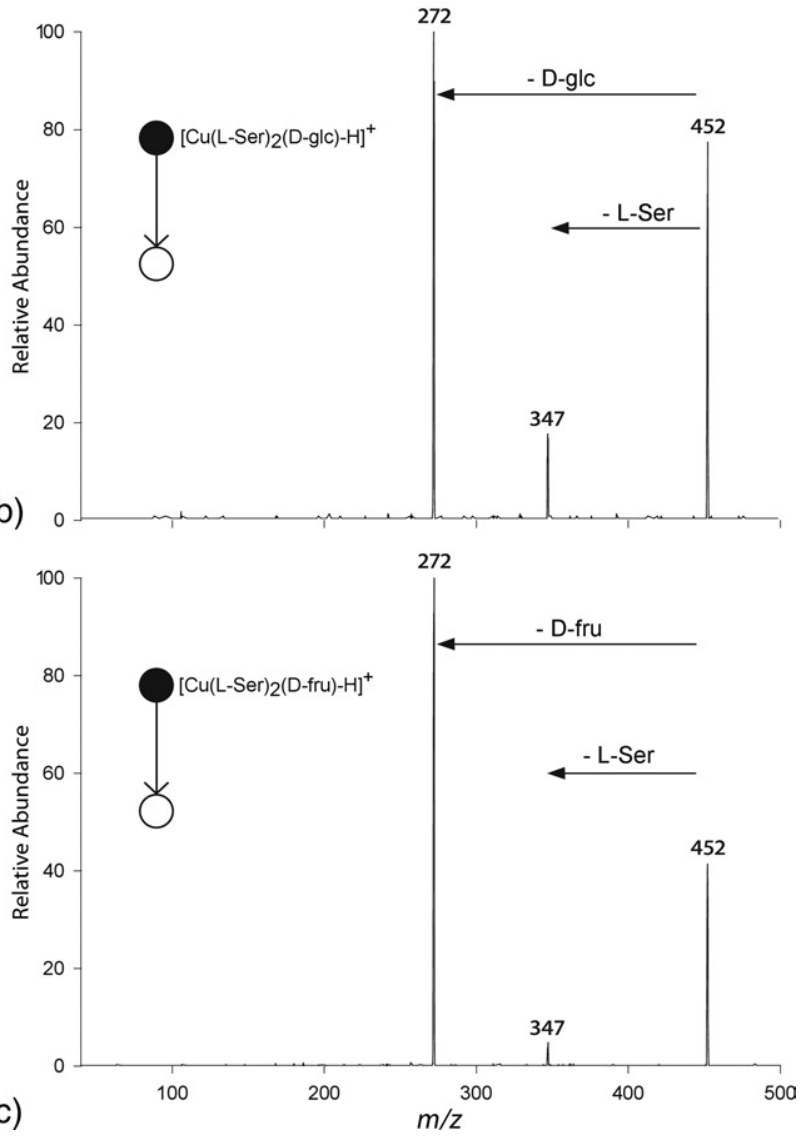

Figure 1. ESI-MS/MS product ion spectra of trimeric complex ions at $\mathrm{m} / \mathrm{z} 452$ containing (a) D-galactose, $\left[\mathrm{Cu}(\mathrm{L}-\mathrm{Ser})_{2}(\mathrm{D}\right.$-gal) $\mathrm{H}]^{+}$, (b) D-glucose, $\left[\mathrm{Cu}(\mathrm{L}-\mathrm{Ser})_{2}(\mathrm{D} \text {-glc })-\mathrm{H}\right]^{+}$, and (c) D-fructose, $\left[\mathrm{Cu}(\mathrm{L}-\mathrm{Ser})_{2}(\mathrm{D}-\mathrm{fru})-\mathrm{H}\right]^{+}$, using a $5 \mathrm{eV}$ collision energy (laboratory frame). precursor was not the base peak in the MS/MS spectra although collision energy was set to the minimal value of $5 \mathrm{eV}$ (laboratory frame), suggesting that the trimeric cluster ion readily dissociates to generate the two expected dimeric product ions.

The two selected systems (Ser $/ \mathrm{Cu}^{2+}$ and $\mathrm{Asp} / \mathrm{Mn}^{2+}$ ) were then tested for quantitation of sugars in binary mixture, using two-point calibration curves $(0 \%$ and $100 \%$ ). In most published studies dealing with chiral discrimination, a linear relationship was demonstrated between $\ln R$ and the content of enantiomers in a sample, as predicted by the kinetic method when assuming the common associated approximations are satisfied. In contrast, deviations from linearity were observed here since errors of up to $43 \%$ were obtained when analyzing binary $50 / 50$ isomeric mixtures. Some cases of nonlinearity have previously been reported [23, 33, 34]. The basis for enantiomer (or isomer) mixture analysis using the kinetic method is the independent formation of the individual trimeric complex ions [35]. The relative abundances of $\left[\mathrm{M}^{\mathrm{II}}(\operatorname{Ref})_{2}\left(\mathrm{~A}_{\mathrm{i}}\right)-\mathrm{H}\right]^{+}$and $\left[\mathrm{M}^{\mathrm{II}}(\operatorname{Ref})_{2}\left(\mathrm{~A}_{\mathrm{j}}\right)-\mathrm{H}\right]^{+}$would indeed reflect the isomeric composition of the analyte $\mathrm{A}$ in solution only if the two $A_{i}$ and $A_{j}$ isomers react equally toward the reference and the transition-metal. Any competition between isomers during the formation of trimeric clusters would induce a deviation from linearity in quantitative analysis, since the proportion of isomers in the gas phase (as involved in the trimer ionic complexes) would no longer reflect that in the liquid phase, as proposed by Zhang et al. [33].

To evidence any competition effect between sugars during the formation of trimeric complexes, ESI-MS experiments were performed to measure the abundance of $\left[\mathrm{M}^{\mathrm{II}}(\operatorname{Ref})_{2}\left(\mathrm{~A}_{\mathrm{i}}\right)-\mathrm{H}\right]^{+}$generated from a series of $\mathrm{A}_{\mathrm{i}}$ standard solutions in the presence of increasing amounts of a second isotopically labeled $\mathrm{A}_{\mathrm{j}}$ isomer. The so-obtained data were plotted as a function of $A_{i}$ concentration, as illustrated in Figure 2 for the example of D-fructose in the presence of D-glucose- $1-{ }^{13} \mathrm{C}$. For a given amount of ${ }^{13} \mathrm{C}$-labeled glucose in solution, the abundance of $\left[\mathrm{Cu}^{\mathrm{II}}(\mathrm{Ser})_{2}(\mathrm{D}-\mathrm{fru})-\mathrm{H}\right]^{+}$varies as a linear function of D-fructose concentration. However, increasing amounts of the labeled isomer was shown to induce an increase of the slope of the D-fructose calibration curve, demonstrating that the presence of D-glucose in the sample strongly modified the production of the trimeric complex ion involving fructose. As shown in Figure $3 a$, the ESI-MS spectrum obtained from a solution containing D-fructose and D-glucose- $1-{ }^{13} \mathrm{C}$ in a $50: 50$ ratio shows that $\left[\mathrm{Cu}^{\mathrm{II}}(\mathrm{Ser})_{2}(\mathrm{D} \text {-fru })-\mathrm{H}\right]^{+}$at $\mathrm{m} / \mathrm{z}$ 452 is nearly two times more abundant than the trimeric complex ion involving the labeled sugar at $m / z 453$ (after correcting this peak intensity from the natural ${ }^{13} \mathrm{C}$ contribution of the $m / z 452$ ion). Similar results were observed for any $A_{i} / A_{j}$ pairs of the studied isomers, showing isomeric discrimination exists in the formation of the trimeric cluster ions in the case of sugars. Since a majority of previous studies with chiral systems show good linearity, in particular to distinguish monosaccha- 


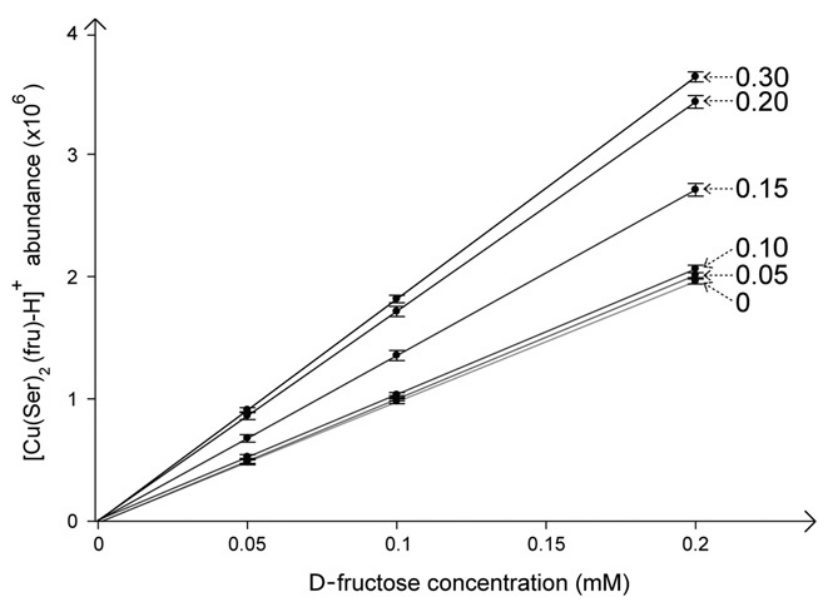

Figure 2. Abundance of the trimeric complex ion containing D-fructose, $\left[\mathrm{Cu}(\mathrm{L}-\mathrm{Ser})_{2}(\mathrm{D} \text {-fru })-\mathrm{H}\right]^{+}$, as a function of D-fructose concentration, for different concentrations of D-glucose- $-1{ }^{13} \mathrm{C}$ in solution, as expressed in $\mathrm{mM}$.

ride enantiomers [14], the nonlinear calibration relationship observed here would be specific to the case of isomers. To check this assumption, the formation of trimeric complex ions was also investigated for a chiral system. It was found that, in contrast to the case of isomer mixture illustrated by Figure 3a, trimeric complex ions involving enantiomers, as for example Lfructose and D-fructose- $1-{ }^{13} \mathrm{C}$, were almost of the same abundance (after isotopic correction) when formed from an equimolar mixture (Figure $3 \mathrm{~b}$ ). This result clearly shows that the competitive formation of trimeric complex ions was due to a distinctive difference in sugar isomers.

Based on Zhang's earlier assumption [33], a procedure aimed at accounting for this competition effect (briefly described hereafter) was successfully applied in the case of amino acid enantiomers [34] and was tested here for quantitative analysis of sugar isomer mixtures. An equilibrium constant, $K_{\mathrm{i}}^{\mathrm{i}, \mathrm{j}}$, is first defined, which relates the proportion of one isomer in the liquid and in the gas phase (respectively, $A_{i, 1}$ and $A_{i, g}$ ) in a mixture of two $A_{i}$ and $A_{j}$ sugars, as follows (eq 4):

$$
\mathrm{A}_{\mathrm{j}, 1} \stackrel{\mathrm{K}_{1, j}^{\mathrm{i}, \mathrm{j}}}{\rightarrow} \mathrm{A}_{\mathrm{i}, \mathrm{g}}
$$

Such a constant should be defined for a given isomer in a specific binary mixture since competition effects may be expected to vary from one isomer pair to another one. As a result, the molar fraction of the $A_{i}$ isomer in the gas-phase, $\alpha_{\mathrm{i}, \mathrm{g}}$, can be expressed as a function of the molar fraction of $\mathrm{A}_{\mathrm{i}}$ in the liquid phase, $\alpha_{\mathrm{i}, 1}$, according to (eq 5):

$$
\alpha_{\mathrm{i}, \mathrm{g}}=\frac{\frac{K_{\mathrm{i}}^{\mathrm{i}, \mathrm{j}}}{K_{\mathrm{i}, \mathrm{j}}^{\mathrm{i}}} \cdot \alpha_{\mathrm{i}, 1}}{\frac{K_{\mathrm{i}}^{\mathrm{i}, \mathrm{j}}}{K_{\mathrm{i}, \mathrm{j}}^{\mathrm{i}}} \cdot \alpha_{\mathrm{i}, 1}+\left(1-\alpha_{\mathrm{i}, 1}\right)}
$$

The correction consists of using $\alpha_{\mathrm{i}, \mathrm{g}}$ instead of the traditionally used $\alpha_{\mathrm{i}, \mathrm{l}}$ parameter, in the Cooks' expression for $\ln R$, where $R$ is the relative branching ratio measured in the CID spectrum of the trimeric ions generated from a sample containing $A_{i}$ and $A_{j}$ isomers (eq 6):

$$
\ln R=\alpha_{\mathrm{i}, \mathrm{g}} \ln \frac{R_{\mathrm{i}}}{R_{\mathrm{j}}}+\ln R_{\mathrm{j}}
$$

where $R_{\mathrm{i}}$ and $R_{\mathrm{j}}$ are the relative branching ratios measured for the $A_{i}$ and $A_{j}$ sugars respectively, when individually analyzed using a defined reference/metal system. By combining eq 5 and eq 6 , the following general expression is obtained for $\ln R$ (eq 7):

$$
\ln R=\frac{\left(\frac{K_{\mathrm{i}}^{\mathrm{j}, \mathrm{j}}}{K_{\mathrm{j}}^{\mathrm{i}, j}} \ln R_{\mathrm{i}}-\ln R_{\mathrm{j}}\right) \cdot \alpha_{\mathrm{i}, 1}+\ln R_{\mathrm{j}}}{\left(\frac{K_{\mathrm{i}, j}^{\mathrm{i}, j}}{K_{\mathrm{j}}^{\mathrm{i}, j}}-1\right) \cdot \alpha_{\mathrm{i}, 1}+1}
$$

As can be seen from eq $7, \ln R$ is a rational function of $\alpha_{\mathrm{i}, 1}$, of the form $\ln R=\left(\mathrm{a} \alpha_{\mathrm{i}, 1}+\mathrm{b}\right) /\left(\mathrm{c} \alpha_{\mathrm{i}, 1}+1\right)$, which only requires a set of three experimental points to be solved.

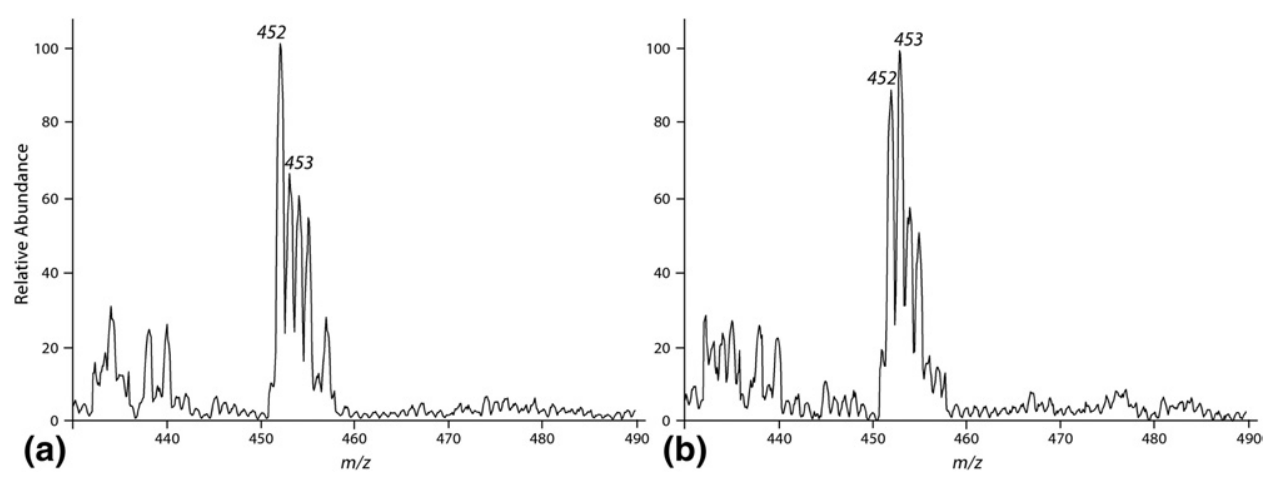

Figure 3. Isotopic pattern of trimeric complex ions in the ESI-MS spectrum obtained from equimolar mixtures of (a) D-fructose and D-glucose $-{ }^{13} \mathrm{C}$ and (b) L-fructose and D-fructose $-{ }^{13} \mathrm{C}$, using the $\mathrm{Cu}^{2+} /$ serine system. 
Data obtained from the three calibration mixtures $(0 \%$, $50 \%$, and $100 \%$ ) previously analyzed were then used for these calculations. The $K_{i}^{i, j} / K_{j}^{i, j}$ constant ratios were graphically determined, as illustrated in Figure 4 for the Ser $/ \mathrm{Cu}^{2+}$ system, and were found to be such as $K_{\mathrm{D} \text {-gal }} /$ $K_{\mathrm{D} \text {-glc }}=2.46$ for the D-galactose/D-glucose mixture, $K_{\mathrm{D} \text {-gal }} / K_{\mathrm{D} \text {-fru }}=2.51$ for the D-galactose $/ \mathrm{D}$-fructose mixture, and $K_{\mathrm{D} \text {-glc }} / K_{\mathrm{D} \text {-fru }}=0.87$ for the D-glucose $/ \mathrm{D}$ fructose mixture. Similar calculations were performed using the Asp $/ \mathrm{Mn}^{2+}$ system and gave rise to $K_{\mathrm{D} \text {-gal }} /$ $K_{\text {D-glc }}=2.33, K_{\mathrm{D} \text {-gal }} / K_{\mathrm{D} \text {-fru }}=1.01$ and $K_{\mathrm{D} \text {-glc }} / K_{\mathrm{D} \text {-fru }}=0.47$, respectively. These values can be used to qualify the extent of competition within each isomer pair. For example, it can be seen that, when present in binary mixtures containing D-galactose, D-fructose and Dglucose would favor the formation of $\left[\mathrm{Cu}^{\mathrm{II}}(\mathrm{Ser})_{2}(\mathrm{D}-\right.$ gal) $-\mathrm{H}]^{+}$to a similar extent. In addition, these data show that competition between two isomers during the formation of trimeric complexes also depends on the selected reference/metal system: the presence of Dfructose would highly favor the inclusion of D-galactose into the complex when using the Ser $/ \mathrm{Cu}^{2+}$ system, while its effect would remain negligible in the formation of $\left[\mathrm{Mn}^{\mathrm{II}}(\mathrm{Asp})_{2}(\mathrm{D}-\mathrm{gal})-\mathrm{H}\right]^{+}$.

Each set of three-point corrected calibration curves were used to quantify different sugar binary samples and results were compared with data obtained from the classical two-point calibrations, as summarized in Table 2. Using two-point calibration curves for quantitation, large errors were usually found but the magnitude of deviation from the actual values was shown to decrease as the relative concentration of the quantified isomer increases, suggesting that the effect of the competing analyte decreases with its relative amount. The only exception to this general trend was the use of the Asp $/ \mathrm{Mn}^{2+}$ system applied to the D-galactose/D-fructose binary mixture: quantitative results obtained for $\mathrm{D}$ galactose were found to be only slightly underesti-

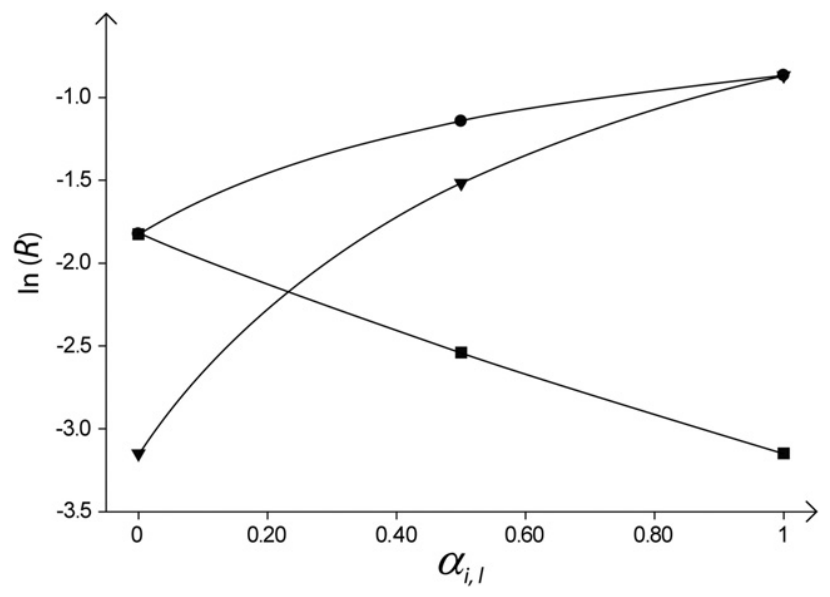

Figure 4. Three-point corrected calibration curves used for quantitative analysis of (filled circle) D-galactose in the presence of D-glucose, (inverted filled triangle) D-galactose in the presence of D-fructose, and (filled square) D-fructose in the presence of D-glucose. mated, with relative errors below $1.2 \%$. This result is consistent with the previously discussed moderate effect of D-fructose on the formation of $\left[\mathrm{Mn}^{\mathrm{II}}(\mathrm{Asp})_{2}(\mathrm{D}-\right.$ gal) $-\mathrm{H}]^{+}$, as indicated by the value of 1.01 determined for $K_{\mathrm{D} \text {-gal }} / K_{\mathrm{D} \text {-fru }}$ in the $\mathrm{D}$-galactose/D-fructose binary mixture using the Asp $/ \mathrm{Mn}^{2+}$ system. In contrast, excellent results were obtained for all sugar isomers when using the three-point corrected calibrations such as those presented in Figure 4. Relative errors were calculated to be in the range $1.6 \%-3.6 \%$ for the lowest sugar molar fraction and $0 \%-1.5 \%$ for the highest relative concentration. Data from Table 2 also show that results of similar quality were obtained using one or the other reference/metal system for isomeric distinction.

Following the same procedure as for binary mixtures, $\ln R$ was expressed as a function of gas-phase molar fraction of each $\mathrm{A}$ isomer present in a ternary sample, from a derivation similar to eq 5 . The soobtained expression for $\ln , R$ in a given reference/metal system, is such as (eq 8):

$$
\begin{aligned}
& \ln R \\
& =\frac{\frac{K_{\mathrm{i}}^{\mathrm{i}, \mathrm{j}, \mathrm{k}}}{K_{\mathrm{k}}^{\mathrm{i}, \mathrm{k}, \mathrm{k}}} \cdot \ln R_{\mathrm{i}} \cdot \alpha_{\mathrm{i}, 1}+\frac{K_{\mathrm{j}}^{\mathrm{i}, \mathrm{j}, \mathrm{k}}}{K_{\mathrm{k}}^{\mathrm{i}, \mathrm{k}, \mathrm{k}}} \cdot \ln R_{\mathrm{j}} \cdot \alpha_{\mathrm{j}, 1}+\left(1-\alpha_{\mathrm{i}, 1}-\alpha_{\mathrm{j}, 1}\right) \cdot \ln R_{\mathrm{k}}}{\left(\frac{K_{\mathrm{i}}^{\mathrm{i}, \mathrm{j}, \mathrm{k}}}{K_{\mathrm{k}}^{\mathrm{i}, \mathrm{j}, \mathrm{k}}}-1\right) \cdot \alpha_{\mathrm{i}, 1}+\left(\frac{K_{\mathrm{j}}^{\mathrm{i}, \mathrm{j}, \mathrm{k}}}{K_{\mathrm{k}}^{\mathrm{i}, \mathrm{j}, \mathrm{k}}}-1\right) \cdot \alpha_{\mathrm{j}, 1}+1}
\end{aligned}
$$

Five experimental points are required to solve the rational function shown in eq 8 , which should be obtained from experiments performed on samples containing the three isomers so that competition occurring in ternary mixtures between sugars for the formation of trimeric complexes could be reflected by the $K^{\mathrm{i}, \mathrm{j}, \mathrm{k}}$ constants. However, although both $A_{j}$ and $A_{k}$ isomers would have an influence on the abundance of the trimeric clusters involving $A_{i}$, it seems reasonable to assume that the presence of $A_{k}$ in the sample would not modify the extend of the effect of $A_{j}$ towards $A_{i}$, as measured in binary mixtures. In other words, a ternary samples could be considered as the mixture of the three pairs $A_{i} / A_{j}, A_{i} / A_{k}$, and $A_{j} / A_{k}$ in terms of competition effects. Based on this assumption, $K$ constant ratios determined from binary mixtures (and thus calibration curves) could be used for each isomer pair in the ternary sample and eq 8 could be simplified to (eq 9):

$$
\begin{aligned}
& \ln R \\
& =\frac{\frac{K_{\mathrm{i}}^{\mathrm{i}, \mathrm{k}}}{K_{\mathrm{k}}^{\mathrm{i}, \mathrm{k}}} \cdot \ln R_{\mathrm{i}} \cdot \alpha_{\mathrm{i}, 1}+\frac{K_{\mathrm{j}}^{\mathrm{j}, \mathrm{k}}}{K_{\mathrm{k}}^{\mathrm{j}, \mathrm{k}}} \cdot \ln R_{\mathrm{j}} \cdot \alpha_{\mathrm{j}, 1}+\left(1-\alpha_{\mathrm{i}, 1}-\alpha_{\mathrm{j}, 1}\right) \cdot \ln R_{\mathrm{k}}}{\left(\frac{K_{\mathrm{i}}^{\mathrm{i}, \mathrm{k}}}{K_{\mathrm{k}}^{\mathrm{i}, \mathrm{k}}}-1\right) \cdot \alpha_{\mathrm{i}, 1}+\left(\frac{K_{\mathrm{j}}^{\mathrm{j}, \mathrm{k}}}{K_{\mathrm{k}}^{\mathrm{j}, \mathrm{k}}}-1\right) \cdot \alpha_{\mathrm{j}, 1}+1}
\end{aligned}
$$


Table 2. Quantification of sugars in binary isomeric mixtures

\begin{tabular}{|c|c|c|c|c|c|}
\hline & \multicolumn{5}{|c|}{ Isomeric fraction $\%(\sigma)^{\mathrm{a}}$} \\
\hline & \multirow[b]{2}{*}{ Actual } & \multicolumn{2}{|c|}{ 2-Point calibration } & \multicolumn{2}{|c|}{ 3-Point corrected calibration } \\
\hline & & $\mathrm{Ser} / \mathrm{Cu}^{2+}$ & $\mathrm{Asp} / \mathrm{Mn}^{2+}$ & $\mathrm{Ser} / \mathrm{Cu}^{2+}$ & Asp/ $\mathrm{Mn}^{2+}$ \\
\hline \multicolumn{6}{|c|}{ D-galactose + D-glucose } \\
\hline \multirow[t]{3}{*}{$\alpha_{\mathrm{D}-\mathrm{gal}, \mathrm{I}}$} & 25 & $43.9(0.7)$ & $43.1(0.5)$ & $24.1(0.5)$ & $25.7(0.7)$ \\
\hline & 50 & $71.1(0.5)$ & $69.8(0.6)$ & $50.0^{\mathrm{b}}(0.7)$ & $50.0^{\mathrm{b}}(0.5)$ \\
\hline & 75 & $87.6(0.6)$ & $87.9(0.9)$ & $74.1(1.1)$ & $76.1(1.0)$ \\
\hline \multicolumn{6}{|c|}{ D-galactose + D-fructose } \\
\hline \multirow[t]{3}{*}{$\alpha_{\text {D-gal,I }}$} & 25 & $46.6(0.8)$ & $24.7(0.8)$ & $25.8(0.6)$ & $25.0(0.5)$ \\
\hline & 50 & $71.5(0.4)$ & $49.4(0.7)$ & $50.0^{\mathrm{b}}(0.6)$ & $50.0^{\mathrm{b}}(0.4)$ \\
\hline & 75 & $88.6(0.3)$ & $74.8(0.4)$ & $75.5(0.6)$ & $75.0(0.5)$ \\
\hline \multicolumn{6}{|c|}{ D-fructose + D-glucose } \\
\hline \multirow[t]{3}{*}{$\alpha_{\mathrm{D}-\text { fru,l }}$} & 25 & $28.2(0.7)$ & $41.3(0.4)$ & $25.4(0.6)$ & $24.4(0.6)$ \\
\hline & 50 & $54.0(1.0)$ & $68.0(0.7)$ & $50.0^{\mathrm{b}}(0.6)$ & $50.0^{\mathrm{b}}(0.6)$ \\
\hline & 75 & $77.9(1.3)$ & $86.4(0.8)$ & $75.4(1.4)$ & $75.5(1.1)$ \\
\hline
\end{tabular}

a Standard deviation calculated on five replicate experiments.

bUsed as standard.

Three ternary samples of various sugar compositions were analyzed. Two $R$ branching ratios were measured for each sample in the CID spectra of trimeric cluster ions generated with each of the two Ser/ $\mathrm{Cu}^{2+}$ and Asp $/ \mathrm{Mn}^{2+}$ systems. As a result, three values could be obtained for $\alpha_{\mathrm{i}, 1}, \alpha_{\mathrm{j}, 1}$, and $\alpha_{\mathrm{k}, \mathrm{l}}$ (which are further averaged), by assigning the $A_{k}$ isomer successively to Dgalactose, D-glucose, and D-fructose. The so-obtained quantitative results are summarized in Table 3 . Consistently good agreement was observed between the actual and the measured values. The quality of these results indicates that the simplifying assumption $\left(K^{\mathrm{i}, \mathrm{j}, \mathrm{k}}=K^{\mathrm{i}, \mathrm{j}}\right)$, which considers that competition effects are defined for any isomer pair regardless of the sample composition, was indeed relevant. This means that the same methodology can be extended to any mixtures containing $n$ sugar isomers, providing that $n-1$ reference/metal

Table 3. Quantification of sugars in ternary isomeric mixtures

\begin{tabular}{|c|c|c|c|}
\hline Sample & Actual & Experimental $(\sigma)^{a}$ & Deviation \\
\hline \multicolumn{4}{|l|}{ I } \\
\hline$\alpha_{\text {D-gal,I }}$ & 33.3 & $33.2(0.5)$ & $-0.3 \%$ \\
\hline$\alpha_{\mathrm{D}-\mathrm{glc}, \mathrm{I}}$ & 33.3 & $34.0(1.0)$ & $+2.1 \%$ \\
\hline$\alpha_{\text {D-fru,l }}$ & 33.3 & $32.8(0.9)$ & $-1.5 \%$ \\
\hline \multicolumn{4}{|l|}{ II } \\
\hline$\alpha_{\text {D-gal,I }}$ & 50 & $49.4(0.6)$ & $-1.2 \%$ \\
\hline$\alpha_{\mathrm{D}-\mathrm{glc}, \mathrm{l}}$ & 35 & $35.9(0.9)$ & $+2.6 \%$ \\
\hline$\alpha_{\text {D-fru, I }}$ & 15 & $14.7(1.1)$ & $-2.0 \%$ \\
\hline \multicolumn{4}{|l|}{ III } \\
\hline$\alpha_{\text {D-gal,I }}$ & 35 & $34.3(0.5)$ & $-2.0 \%$ \\
\hline$\alpha_{\mathrm{D}-\mathrm{glc}, \mathrm{l}}$ & 15 & $15.8(1.1)$ & $+5.3 \%$ \\
\hline$\alpha_{\text {D-fru,l }}$ & 50 & $49.9(1.2)$ & $-0.2 \%$ \\
\hline
\end{tabular}

${ }^{a}$ Standard deviation calculated on five replicate experiments. systems are available to evaluate competition effects between any two sugars.

\section{Conclusions}

The use of the kinetic method for isomeric distinction of sugars was demonstrated using divalent metal cations and amino acids as the reference. Although the choice of the reference remained empirical, it should be noted that the two selected systems, which were shown to have the highest ability to distinguish the studied isomers, involve a reference with functional similarity with the sugar analytes (serine and aspartic acid both possess a hydroxyl group). The independent formation of the individual trimeric complex ions forms the basis for isomeric mixture analysis using the kinetic method. Although this requirement was not satisfied in the cases examined here, a correction procedure was successfully applied, which takes into account competition effects between two isomers in mixture for the formation of the trimeric complexes. The good accuracy of quantitative results obtained in ternary mixtures using the correction factors established for binary mixtures suggest that the same methodology can be extended to the analysis of more complex sugar isomer samples.

\section{Acknowledgments}

L.C. acknowledges support from Spectropole, the Analytical Facility of Aix-Marseille University, by allowing a special access to the instruments purchased with European funding (FEDER OBJ2142-3341). 


\section{Appendix A Supplementary Material}

Supplementary material associated with this article may be found in the online version at doi:10.1016/ j.jasms.2009.09.002.

\section{References}

1. Oppenheimer, S. B. Cancer: A Biological and Clinical Introduction. Pearson: Boston, 2004; pp 39-70.

2. Oppenheimer, S. B. Cellular Basis of Cancer Metastasis: A Review of Fundamentals and New Advances. Acta Histochem. 2006, 108, 327-334.

3. Oppenheimer, S. B.; Alvarez, M.; Nnoli, J. Carbohydrate-Based Experimental Therapeutics for Cancer, HIV/AIDS, and Other Diseases. Acta Histochem. 2008, 110, 6-13.

4. De Clercq, E. Antiviral Agents Active Against Influenza A Viruses. Nat. Rev. Drug Discov. 2006, 5, 1015-1025.

5. Kilcoyne, M.; Joshi, L. Carbohydrates in Therapeutics. Cardiovasc. Hematol. Agents Med. Chem. 2007, 5, 186-197.

6. Simerska, P.; Abdel-Aal, A. B. M.; Fujita, Y.; Batzloff, M. R.; Good, M. F.; Toth, I. Synthesis and In Vivo Studies of Carbohydrate-Based Vaccines Against Group A Streptococcus. Biopolymers 2008, 90, 611-616.

7. Masuda, T.; Kitahara, K.; Aikawa, Y.; Arai, S. High-Performance Liquid Chromatographic Separation of Carbohydrates on a Stationary Phase Prepared from Polystyrene-Based Resin and Novel Amines. J. Chromatogr. A 2002, 961, 89-96.

8. Agblevor, F. A.; Hames, B. R.; Schell, D.; Chum, H. L. Analysis of Biomass Sugars Using a Novel HPLC Method. Appl. Biochem. Biotechnol. 2007, 136, 309-326.

9. Menges, R. A.; Armstrong, D. W. Chromatographical Optical Resolution on Polysaccharide Carbamate Phases. In Chiral Separations by Liquid Chromatography. Vol 471, Ahuja, S., Ed.; American Chemical Society: Washington, DC, 1991; pp 67-100.

10. Zhu, X. Y. Sato, T. The Distinction of Underivatized Monosaccharides Using Electrospray Ionization Ion Trap Mass Spectrometry. Rapid Commun. Mass Spectrom. 2007, 21, 191-198.

11. Gaucher, S. P.; Leary, J. A. Stereochemical Differentiation of Mannose, Glucose, Galactose, and Talose Using Zinc(II) Diethylenetriamine and ESI-Ion Trap Mass Spectrometry. Anal. Chem. 1998, 70, 3009-3014.

12. Salpin, J. Y.; Tortajada, J. Structural Characterization of Hexoses and Pentoses Using Lead Cationization. An Electrospray Ionization and Tandem Mass Spectrometric Study. J. Mass Spectrom. 2002, 37, 379-388.

13. March, R. E.; Stadey, C. J. A Tandem Mass Spectrometric Study of Saccharides at High Mass Resolution. Rapid Commun. Mass Spectrom. 2005, 19, 805-812.

14. Augusti, D. V.; Carazza, F.; Augusti, R.; Tao, W. A.; Cooks, R. G. Quantitative Chiral Analysis of Sugars by Electrospray Ionization Tandem Mass Spectrometry Using Modified Amino Acids as Chiral Reference Compounds. Anal. Chem. 2002, 74, 3458-3462.

15. Tao, W. A.; Cooks, R. G. Chiral Analysis by MS. Anal. Chem. 2003, 75, 25A-31A.

16. Tao, W. A.; Wu, L. M.; Cooks, R. G. Differentiation and Quantitation of Isomeric Dipeptides by Low-Energy Dissociation of Copper(II)-Bound Complexes. J. Am. Soc. Mass Spectrom. 2001, 12, 490-496.
17. Wu, L. M.; Lemr, K.; Aggerholm, T.; Cooks, R. G. Recognition and Quantification of Binary and Ternary Mixtures of Isomeric Peptides by the Kinetic Method: Metal Ion and Ligand Effects on the Dissociation of Metal-Bound Complexes. J. Am. Soc. Mass Spectrom. 2003, 14, 152-160.

18. Wu, L. M.; Meurer, E. C.; Young, B.; Yang, P. X.; Eberlin, M. N.; Cooks, R. G. Isomeric Differentiation and Quantification of $\square, \beta$-Amino AcidContaining Tripeptides by the Kinetic Method: Alkali Metal-Bound Dimeric Cluster Ions. Int. J. Mass Spectrom. 2004, 231, 103-111.

19. Schug, K. A.; Lindner, W.; Lemr, K. Isomeric Discrimination of Arginine-Containing Dipeptides Using Electrospray Ionization-Ion Trap Mass Spectrometry and the Kinetic Method. J. Am. Soc. Mass Spectrom. 2004, 15, 840-847.

20. Hyyrylainen, A. R. M.; Pakarinen, J. M. H.; Fulop, F.; Vainiotalo, P. Diastereochemical Differentiation of Some Cyclic and Bicyclic $\beta$-Amino Acids, Via the Kinetic Method. J. Am. Soc. Mass Spectrom. 2009, 20, $34-41$.

21. Cooks, R. G.; Patrick, J. S.; Kotiaho, T.; McLuckey, S. A. Thermochemical Determinations by the Kinetic Method. Mass Spectrom. Rev. 1994, 13, 287-339.

22. Cooks, R. G.; Wong, P. S. H. Kinetic Method of Making Thermochemical Determinations: Advances and Applications. Acc. Chem. Res. 1998, 31, 379-386.

23. Tao, W. A.; Zhang, D. X.; Nikolaev, E. N.; Cooks, R. G. Copper(II)Assisted Enantiomeric Analysis of D,L-Amino Acids Using the Kinetic Method: Chiral Recognition and Quantification in the Gas Phase. J. Am. Chem. Soc. 2000, 122, 10598-10609.

24. Tao, W. A.; Gozzo, F. C.; Cooks, R. G. Mass Spectrometric Quantitation of Chiral Drugs by the Kinetic Method. Anal. Chem. 2001, 73, 1692-1698.

25. Harvey, D. J. Ionization and Collision-Induced Fragmentation of NLinked and Related Carbohydrates Using Divalent Canons. J. Am. Soc. Mass Spectrom. 2001, 12, 926-937.

26. Cerda, B. A.; Wesdemiotis, C. The Relative Copper(I) Ion Affinities of Amino-Acids in the Gas Phase. J. Am. Chem. Soc. 1995, 117, 9734-9739.

27. Wu, L. M.; Meurer, E. C.; Cooks, R. G. Chiral Morphing and Enantiomeric Quantification in Mixtures by Mass Spectrometry. Anal. Chem 2004, 76, 663-671.

28. Carroll, J. A.; Willard, D.; Lebrilla, C. B. Energetics of Cross-Ring Cleavages and Their Relevance to the Linkage Determination of Oligosaccharides. Anal. Chim. Acta 1995, 307, 431-447.

29. Smith, G.; Leary, J. A. Mechanistic Studies of Diastereomeric Nickel(II) N-Glycoside Complexes Using Tandem Mass Spectrometry. J. Am. Chem. Soc. 1998, 120, 13046-13056.

30. Madhusudanan, K. P. Tandem Mass Spectra of Ammonium Adducts of Monosaccharides: Differentiation of Diastereomers. J. Mass Spectrom. 2006, 41, 1096-1104.

31. Zhang, D. X. Tao, W. A. Cooks, R. G. Chiral Resolution of D- and L-Amino Acids by Tandem Mass Spectrometry of Ni(II)-Bound Trimeric Complexes. Int. J. Mass Spectrom. 2001, 204, 159-169.

32. Wu, L. M.; Cooks, R. G. Chiral Analysis Using the Kinetic Method with Optimized Fixed Ligands: Applications to Some Antibiotics. Anal. Chem. 2003, 75, 678-684.

33. Zhang, M. Y.; Kerns, E.; McConnell, O. Observation of Enantiomeric Formation of Trimeric Complex Ions [CuII(Phe)(Pro)2 - H] + using ESI. Proceedings of the 51st ASMS Conference on Mass Spectrometry and Allied Topics; Montreal, Quebec, Canada, June 2003.

34. Lemr, K.; Ranc, V.; Frycak, P.; Bednar, P.; Sevcik, J. Chiral Analysis by Mass Spectrometry Using the Kinetic Method in Flow Systems. J. Mass Spectrom. 2006, 41, 499-506.

35. Wu, L. M.; Tao, W. A.; Cooks, R. G. Kinetic Method for the Simultaneous Chiral Analysis of Different Amino Acids in Mixtures. J. Mass Spectrom. 2003, 38, 386-393. 